\title{
Characterization of volatile organic gunshot residues in fired handgun cartridges by headspace sorptive extraction
}

\author{
Matteo Gallidabino $^{1}$ - Francesco S. Romolo ${ }^{2}$ - Celine Weyermann ${ }^{1}$
}

Received: 27 March 2015 /Revised: 18 June 2015 / Accepted: 22 June 2015 /Published online: 14 July 2015

(C) Springer-Verlag Berlin Heidelberg 2015

\begin{abstract}
In forensic investigation of firearm-related cases, determination of the residual amount of volatile compounds remaining inside a cartridge could be useful in estimating the time since its discharge. Published approaches are based on following the decrease of selected target compounds as a function of time by using solid phase micro-extraction (SPME). Naphthalene as well as an unidentified decomposition product of nitrocellulose (referred to as "TEA2") are usually employed for this purpose. However, reliability can be brought into question given their high volatility and low reproducibility of the extracted procedure. In order to identify alternatives and therefore develop improved dating methods, an extensive study on the composition and variability of volatile residues in nine different types of cartridges was carried out. Analysis was performed using headspace sorptive extraction (HSSE), which is a more exhaustive technique compared to SPME. One hundred sixty six compounds were identified (several of which for the first time), and it was observed that the final compositional characteristics of each residue were strongly dependent on its source. Variability of single identified compounds within and between different types of cartridge as well as their evolution over time were also studied.
\end{abstract}

Electronic supplementary material The online version of this article (doi:10.1007/s00216-015-8874-0) contains supplementary material, which is available to authorized users.

Matteo Gallidabino

matteo.gallidabino@unil.ch

1 École des Sciences Criminelles, Institut de Police Scientifique, University of Lausanne, Bâtiment Batochime,

1015 Lausanne-Dorigny, Switzerland

2 Section of Legal Medicine, Department SAIMLAL, Sapienza Università di Roma, Viale Regina Elena 336, 00161 Rome, Italy
Many explosion products containing up to four aromatic rings were found to be globally present in high proportions. Twenty-seven of them (excluding naphthalene) also presented detectable decreases during the first $24 \mathrm{~h}$. Therefore, they could be used as complementary target analytes in future dating methods.

Keywords Forensic science $\cdot$ Firearm · Gunshot residue · Sorptive extraction $\cdot$ HSSE-GC/MS $\cdot$ Dating $\cdot$ Time since discharge

\section{Introduction}

In the forensic investigation of criminal cases, residual materials released during firearm discharges can be exploited in order to identify a person involved in a gunfire event, estimate a shooting distance, determine the ammunition type or to estimate the time elapsed since discharge [1-3]. These residual materials are collectively known as gunshot residue (GSR) and mainly consist of flakes from partially reacted smokeless powder, vaporized species from all the cartridge elements, microscopic metallic particles and explosion products from gunpowder and primer mixtures [1-3]. Given their importance in forensic science, the specific composition and variability of some of them were thoroughly studied. This is the case for solid particulate residues (i.e. smokeless powder flakes and microscopic metallic particles), which are generally used to identify a shooter and/or estimate a shooting distance [4-7].

Early researches in the field of volatile GSR compounds mainly referred to environmental and health issues [8,9], neglecting the areas of applications in forensic science. More recently, it was found that their diffusion kinetics could be useful to estimate the time since a cartridge or firearm was last 
discharged [10-13]. Since then, choosing the most accurate target compounds has been a central concern, and questions concerning composition and variability of volatile GSR compounds has become again of great interest. It is well known that the main compounds released during the cartridge discharge are oxidation products. Sequential explosion of the various organic species composing the gunpowder and primer mixtures produces very hot gases, essentially consisting of $\mathrm{H}_{2} \mathrm{O}, \mathrm{CO}, \mathrm{CO}_{2}, \mathrm{H}_{2}$ and $\mathrm{N}_{2}[9,14]$. However, low levels of many other heavier compounds were also found in GSR vapours. Most of them are pyrolitic byproducts, the formation of which is due to the oxygen-deficient and high-temperature conditions persisting during the discharge. Such extreme conditions lead to the formation of radicals, which could add to other stable molecules and set in motion a waterfall mechanism resulting in the formation of larger compounds $[15,16]$. Benzene, toluene and styrene are generally the first species to be formed by the stabilization of unsaturated aliphatic radical species through cyclization. Then, successive additions can lead (through further cyclization phenomena) to naphthalene and from there to the synthesis of other heavier polycyclic aromatic hydrocarbons (PAHs). Branched or substituted derivatives of the previous compounds (e.g. methylnaphthalenes) can be released as side-products; similarly, heteroatoms can take part in the reaction mechanism and be incorporated in the structures of the final products [17, 18]. Hundreds of PAHs from two up to six rings substituted derivatives of benzene, and heterocyclic compounds have been identified in GSRs. Particularly, Ase et al. [8] identified more than 100 different trace species in the exhaust of a military rifle and an anti-tank gun using trapping methods followed by gas chromatography coupled to mass spectrometry (GC/MS) and high-performance liquid chromatography with ultraviolet detection (HPLC/UV). Andrasko et al. [10] confirmed the presence of some of these compounds in shotgun barrels by in situ sampling of vapours with headspace solid phase microextraction (SPME), followed by analysis with GC coupled to thermal electron analyser (TEA), flame ionization detector (FID) or mass spectrometry (MS). Using SPME-GC/MS, Weyermann et al. [19] characterized the residues of two types of $9 \mathrm{~mm}$ Parabellum ammunition and reported the identification of 34 compounds (confirmed with reference standards). Recently, Gallidabino et al. [20] looked for specific compounds in GSRs and identified 51 molecules in the headspace of fired cartridges using headspace sorptive extraction (HSSE) followed by GC/MS.

Most of the published approaches for estimating the time since discharge were based on the selection of target analytes amongst the previously identified molecules, and the comparison of their residual quantity against ageing profiles obtained from pertinent reference material (i.e. the firearm/cartridges set presumably used for committing the crime). Thus, naphthalene and an unidentified decomposition product of nitrocellulose (referred to as "TEA2") were regarded as promising in order to estimate the time elapsed since a shotgun, rifle or related ammunition were last fired $[10-12,21]$. However, their usefulness for dating the discharge of handguns and smaller cartridges was questioned because they disappear too rapidly (few hours) and their amounts are not reproducible enough $[13,19]$. Until now, no comprehensive qualitative and quantitative studies on GSR compositions released by handgun cartridges have ever been carried out to the best of our knowledge, leaving a gap on other possible target compounds.

Thus, this research aimed at comprehensively evaluating the composition and variability of volatile GSRs produced by nine different types of ammunition belonging to two handgun calibres (.357 Magnum and .45 ACP). At first, compounds found in cartridges after discharge were extracted and identified. As sampling method, HSSE was selected. HSSE is a recent extraction technique, which was introduced for trace and ultra-trace analysis [22]. While it is based on the same principle of headspace SPME, the extraction support in HSSE is not a thin fibre but a magnetic stir bar coated with a larger volume of polydimethylsiloxane (PDMS) phase (up to 110 vs $0.5 \mu \mathrm{L}$ for SPME) [22]. For this reason, limits of detection are improved and the discrimination towards more polar compounds is generally reduced, making HSSE a very valuable technique for extensive characterization of various sample types, as recently proved in many analytical domains [22-24]. The method was recently applied to volatile GSR compounds, leading to a good extraction recovery for some selected compounds [20]. Following the identification step, intra-variability (i.e. variability within the same firearm and cartridge set), inter-variability (i.e. variability between different firearm and cartridge sets) and evolution over time of the identified compounds were studied in order to select promising target molecules for dating purposes.

\section{Materials and methods}

\section{Reference substances, solvents and ammunition}

Pure standards of 55 compounds were purchased (see Table S1 in the Electronic Supplementary Material (ESM) for details). For each substance, a working standard solution was prepared at a concentration of $1 \mathrm{mg} \mathrm{mL}^{-1}$ in methanol (puriss. grade) purchased from Sigma/Aldrich (Buchs, Switzerland), except for anthracene, chrysene and benzo[a]pyrene which were dissolved in chloroform (purum grade) also purchased from Sigma/Aldrich. Nitroglycerin was already dissolved at a concentration of $1 \mathrm{mg} \mathrm{mL}^{-1}$ in a mixture of ethanol/methanol (97:3).

Nine different types of ammunition were purchased during 2011 from sellers in Switzerland (see Table 1). Five of them 
Table 1 Cartridges selected for the study, their characteristics and the composition of their smokeless powders determined by GC/MS ( $N G$ nitroglycerine, $D P A$ diphenylamine, $E C$ ethylcentralite, $D B P$ dibutyl phthalate, 2NDPA 2-nitrodiphenylamine, AKII 1-methyl-3,3diphenylurea (akardite II), $D F$ dioctyl fumerate)

\begin{tabular}{|c|c|c|c|c|c|c|c|c|c|c|c|c|}
\hline \multirow[t]{2}{*}{ Abbreviation } & \multicolumn{5}{|l|}{ Characteristics } & \multicolumn{7}{|c|}{ Smokeless powder composition } \\
\hline & Calibre & Brand & $\begin{array}{l}\text { Bullet } \\
\text { mass [gr] }\end{array}$ & Bullet type & $\begin{array}{l}\text { Powder } \\
\text { weight [gr] }\end{array}$ & NG & DPA & $\mathrm{EC}$ & DBP & 2NDPA & AKII & DF \\
\hline Ge45 & $.45 \mathrm{ACP}$ & Geco & 230 & FMJ & 6.0 & M & $\mathrm{m}$ & M & - & - & - & - \\
\hline $\operatorname{Pm} 45$ & $.45 \mathrm{ACP}$ & PMC & 230 & FMJ & 5.1 & M & M & - & - & - & - & - \\
\hline $\operatorname{Re} 45$ & $.45 \mathrm{ACP}$ & Remington UMC & 230 & FMJ & 4.8 & M & M & - & M & - & M & - \\
\hline Se45 & $.45 \mathrm{ACP}$ & Sellier \& Bellot & 230 & FMJ & 5.0 & M & M & - & M & $\mathrm{m}$ & - & - \\
\hline Ma45 & $.45 \mathrm{ACP}$ & Magtech & 230 & FMJ & 5.5 & - & - & M & - & - & - & - \\
\hline Ge357 & .357 Magnum & Geco & 158 & FMJ & 6.3 & M & M & M & - & - & M & - \\
\hline $\operatorname{Se} 357$ & .357 Magnum & Sellier \& Bellot & 158 & FMJ & 6.2 & M & M & - & M & - & - & - \\
\hline $\mathrm{Sa} 357$ & .357 Magnum & Samson & 125 & JSP & 17.2 & M & M & M & M & $\mathrm{m}$ & - & $\mathrm{m}$ \\
\hline Ma357 & .357 Magnum & Magtech & 158 & FMJ & 14.6 & M & M & M & M & - & - & - \\
\hline
\end{tabular}

"M" indicates a major compound ( $>1 \%$ of the total area count) and " $\mathrm{m}$ " a minor compound $(0.2-1 \%$ of the total area count); "FMJ" indicates full metal jacket bullets and "JSP" jacket soft point bullets. Masses are given in grains ( 1 grain=64.80 mg)

belonged to .45 ACP calibre (producers: Geco, PMC, UMC, Sellier \& Bellot and Magtech) and the remaining four to .357 Magnum (producers: Geco, Sellier \& Bellot, Samson and Magtech). From each ammunition box, two cartridges were opened using a kinetic hammer, and the smokeless powder analysed by GC/MS using a method adapted from Romolo [25] (see results in Table 1).

\section{Test shootings}

Test shootings were carried out using a Colt 1911 semiautomatic pistol (.45 ACP) and a Colt Python revolver (.357 Magnum). Before starting the test shootings, firearms were carefully cleaned with dry cleaning patches. Then, test cartridges were fired by singly loading them in the magazine/ cylinder. Cartridges were handled while wearing latex gloves in order to minimize contaminations from hands. Latex gloves were preferred over nitrile ones since preliminary tests showed that the latter introduced several unwanted impurities in samples, especially long-chain aliphatic compounds. Weapons were never greased between the different test shootings.

Spent cartridges analysed at time $t=0 \mathrm{~h}$ were immediately recovered after discharge and put in $20 \mathrm{~mL}$ HSSE-dedicated crimp glass vials (Gerstel, Sursee, Switzerland). These vials were found to be suitable because their large opening (i.e. $13 \mathrm{~mm}$ ) fits well with most handgun calibres. A stir bar was suspended with the aid of a special glass insert (Gerstel) to the headspace of each vial containing a fired cartridge. Then, vials were rapidly closed with $20 \mathrm{~mm}$ crimp caps equipped with $3.0 \mathrm{~mm}$ polytetrafluoroethylene/silicon septa (Gerstel). Glassware was previously conditioned in a ventilated laboratory oven at $80^{\circ} \mathrm{C}$ for $8 \mathrm{~h}$. Some analyses were also performed on fired cartridges aged for $24 \mathrm{~h}(t=24 \mathrm{~h})$ in an air-conditioned laboratory kept at a temperature of about $20^{\circ} \mathrm{C}$.

\section{HSSE extraction of spent cartridges}

HSSE stir bars are commercialized under the name of "Twister ${ }^{\complement}$ " by Gerstel. The largest PDMS-coated HSSE stir bars available $(2 \mathrm{~cm}$ length with a $1 \mathrm{~mm}$ coating thickness, corresponding to a PDMS volume of $110 \mu \mathrm{L}$ ) were purchased. Stir bars were always thermo-conditioned before use. To do this, they were put in ad hoc glass desorption tubes (Gerstel) and placed in a Gerstel TC tube conditioner. The conditioning procedure suggested by the producer ( $30 \mathrm{~min}$ at laboratory temperature, followed by $90 \mathrm{~min}$ at $300{ }^{\circ} \mathrm{C}$ and about 60 min to cool down) was used.

Preliminary tests indicated that a sampling temperature of $80^{\circ} \mathrm{C}$ promotes extraction of less volatile compounds as opposed to a temperature of $20^{\circ} \mathrm{C}$, whereby the recovery of the most volatile compounds decreases in some cases. Different specimens of the same type of ammunition (same box) were thus analysed at the two temperatures in order to guarantee the detection and identification of a larger range of compounds. For extraction at $20{ }^{\circ} \mathrm{C}$, closed vials were put in an airconditioned laboratory with controlled temperature, while extractions at $80{ }^{\circ} \mathrm{C}$ were performed in a ventilated laboratory oven. Extraction time was set at $72 \mathrm{~h}$. Before analysis, the sample vials were reopened, stir bars were removed and placed in reconditioned desorption tubes. Finally, the tubes were capped with special transportation adapters (Gerstel) and placed on the GC tray for GC/MS analysis. For each type of ammunition, three different cartridges from the same box were analysed per temperature. Procedural blanks were also systematically carried out. These consisted of empty vials, 
which were handled in the same way as those used for sampling the cartridges, and had been in contact with the same environments. Three blanks per extraction condition were analysed.

\section{Analysis of stir bars}

Stir bars were thermally desorbed using a Gerstel TDU thermal desorption unit, connected to a Gerstel CIS-4 programmed temperature vaporizing injector. These devices were mounted on an Agilent 7890A gas chromatograph coupled to an Agilent 5975C mass selective detector (Agilent Technologies, Basel, Switzerland). The system was also equipped with a Gerstel MPS multi-purpose sampler, which was used to automatically load tubes containing stir bars into the TDU.

Desorption mode was splitless, desorption flow

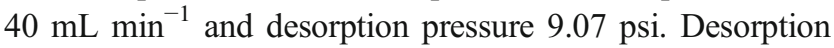
ramp was programmed as follows: $20{ }^{\circ} \mathrm{C}$ for $0.5 \mathrm{~min}$, increased to $250^{\circ} \mathrm{C}$ at $60^{\circ} \mathrm{C} \mathrm{min}^{-1}$ and held at this temperature for $10 \mathrm{~min}$ (total desorption time of $14.3 \mathrm{~min}$ ). The transfer line temperature between TDU and CIS- 4 was $280^{\circ} \mathrm{C}$. Liners for CIS-4 were obtained from Gerstel and packed with quartzwool. The cryo-focusing temperature was set at $-80^{\circ} \mathrm{C}$. The PTV injection ramp programming was as follows: $-80^{\circ} \mathrm{C}$ for 0 min, increased to $300{ }^{\circ} \mathrm{C}$ at $600{ }^{\circ} \mathrm{C} \mathrm{min}^{-1}$ and held at this temperature for $1.37 \mathrm{~min}$ (total injection time: $2 \mathrm{~min}$ ). Splitless mode was used during this time. After injection, the injector was additionally programmed to decrease at a rate of $720{ }^{\circ} \mathrm{C} \mathrm{min}{ }^{-1}$ to $270{ }^{\circ} \mathrm{C}$ and held at this temperature for $10 \mathrm{~min}$ in split mode in order to condition the liner for the next injection.

GC separation was performed on a HP-5MS (30 m $\times$ $0.25 \mathrm{~mm} \times 0.25 \mu \mathrm{m}$ ) column from Agilent. The carrier gas was helium, and column flow was maintained at $1.2 \mathrm{~mL} \mathrm{~min}{ }^{-1}$. The oven ramp was programmed as follows: $40{ }^{\circ} \mathrm{C}$ for $2 \mathrm{~min}$, increased to $100^{\circ} \mathrm{C}$ at $10^{\circ} \mathrm{C} \mathrm{min}^{-1}$, increased to $200^{\circ} \mathrm{C}$ at $5{ }^{\circ} \mathrm{C} \mathrm{min}^{-1}$, increased to $280^{\circ} \mathrm{C}$ at $5^{\circ} \mathrm{C} \mathrm{min}^{-1}$ and held at this temperature for $10 \mathrm{~min}$ (total chromatographic time: $46 \mathrm{~min}$ ). The transfer line between the column and the MS was set at $280{ }^{\circ} \mathrm{C}$. Ionization was carried out through electron impact (EI). Masses were scanned from $\mathrm{m} / \mathrm{z} 40$ to 500 without solvent delay. MS source and quadrupole temperatures were 230 and $150{ }^{\circ} \mathrm{C}$, respectively.

\section{Injection of standard solutions}

In order to inject the standard solutions, a desorption tube was equipped with special glass insert and transportation adapter for liquid injection (both furnished by Gerstel). Before analysis, the tube was automatically inserted into the TDU, and $1 \mu \mathrm{L}$ of solution was injected into the insert. GC/MS parameters were the same as mentioned above, except for the CIS-4 cryo-focusing temperature, which was set to $0{ }^{\circ} \mathrm{C}$ in order to vent solvents during desorption. Moreover, a solvent delay of $4 \mathrm{~min}$ and split mode were adopted.

\section{Data processing}

Chromatograms acquired at time $t=0 \mathrm{~h}$ were used for peak identification. These were analysed using the Enhanced Data Analysis software provided by Agilent. Preliminary identification of the mass spectra of the eluted peaks was attempted with the NIST08 library. Hits were evaluated by visual inspection of the corresponding spectra. Afterward, liquid standards were injected to confirm the identity of compounds of particular interest. Detection of a compound was accepted if its mass fragmentation pattern was coherent with the results of the library search (additionally, retention time had to match for the molecules with available standards).

After identification, target ions were selected for all the compounds and the corresponding peak areas were extracted. The presence of a compound in a particular type of ammunition was accepted if the intensity of its target ion was greater than the average signals in the procedural blanks plus three times the standard deviation [26] in at least one of the analysed cartridges.

For further statistical analyses, the observed peak areas were normalized to the respective cartridge total sum (unless otherwise indicated in-text). In this way, proportions were calculated. Principal component analysis (PCA) was applied on data in order to study the composition variability. For this purpose, variables were further mean-centred and scaled with their standard deviations. In order to find molecules with significant decreases over time, specimens belonging to two types of ammunition (Ma45 and Ge45) were aged for $24 \mathrm{~h}$ and a Student $t$ test was performed on the slope passing through the values measured at $t=0$ and $24 \mathrm{~h}$. If the slope was negative and significantly different from zero $(\alpha=0.1)$, the hypothesis of decrease was accepted.

\section{Results and discussion}

\section{Identification of the volatile compounds in GSR}

Spent cartridges from nine types of ammunition were extracted using HSSE at two different temperatures $\left(20\right.$ and $\left.80^{\circ} \mathrm{C}\right)$. The obtained chromatograms were generally characterized by a large number of peaks. This is well illustrated in Fig. 1, where an example of total ion chromatogram (TIC) is shown.

One hundred sixty six peaks were found to be recurrent between TICs from different cartridges. Their identities are reported in Table S2 in the ESM. It is noteworthy that the analysed GSRs presented a high variety of aromatic molecules. In fact, 109 of the 166 recurrently detected compounds have at 
Fig. 1 Example of HSSE chromatogram of a fired cartridge (Samson .357 Magnum, extracted at $80{ }^{\circ} \mathrm{C}$ )

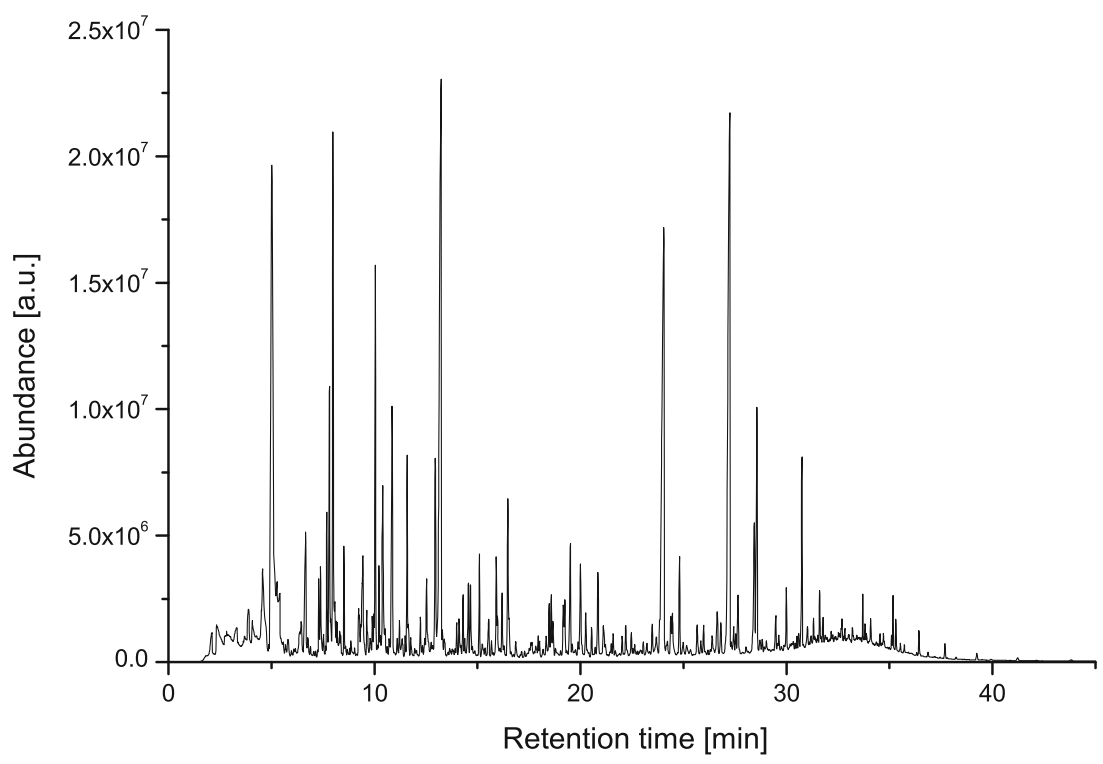

least one aromatic ring in their structure. As already reported in previous works, PAHs were the most diversified group. Nonbranched PAHs with up to five rings were identified. Most of them were already reported in the literature as being released after the discharge of handgun cartridges (e.g. naphthalene, biphenyl, acenaphthene, phenanthrene, pyrene, benzo[a]pyrene) $[10,19,20]$. Indane was previously identified solely in the exhaust of military rifle [8], while azulene, diphenylmethane, phenylnaphthalene and $4 \mathrm{H}-$ cyclopenta[def]phenanthrene were found for the first time in this study. Many branched and substituted derivatives of some PAHs (especially naphthalene) were also observed. 1- and 2Methylnaphthalene, 1- and 2-naphthalenecarbonitrile, as well as some isomers of dimethylnaphthalene were already reported in the literature [18-20] and found in the GSRs of all the cartridges. Additionally, the improved sensitivity of the HSSE method allowed the detection of diisopropylnaphthalene, methylindene, 1,2,3,4-tetrahydro-1,1,6-trimenthylnaphthalene and some isomers of the ethenylnaphthalene. Benzene and its derivatives were also very common between the different residues. In fact, benzene, ethylbenzene, styrene and xylene isomers were always identified, while toluene was found in the exhausts of eight out of nine types of cartridges.

Several molecules containing hetero-atoms were observed. As previously reported in the literature, nitrogen-containing PAH homologs were a relatively diversified group. Quinoline and carbazole were observed in the residues of all types of cartridges, while isoquinoline was only detected in three of them. Phenazine was previously observed in the exhaust of smokeless powder after pyrolysis and incineration [17], but never found in GSRs prior to our study. Methylpyridine was already reported to be present in the exhausts of military rifles [8], but never in those of spent cartridges. Methylimidazole and benzoquinoline isomers were never reported before. Molecules with nitrogen-containing functional groups were also frequent. Aromatic nitriles were a particularly represented class. Amongst them, benzonitrile and benzyl nitrile, as well as the isomers of tolunitrile, dicyanobenzene and naphthalenecarbonitrile were common to all residues. This is in agreement with previous studies [19, 20]. Ethenylbenzonitrile was never reported before, but two of its isomers were found in all residues. The large number of nitrogenized species is compatible with the characteristics of the exploding materials. In fact, smokeless powders are rich in nitrogen-containing substances, such as nitroesters (i.e. explosives) and aromatic amines/ureas (i.e. stabilizers). Nitrogen atoms from all these compounds can thus participate in the reaction mechanism and therefore be found in the structures of the final products.

Many amines, ureas and nitro-compounds were identified. Amongst amines and ureas, the three main stabilizers used in smokeless powders were detected, i.e. diphenylamine, ethylcentralite and 1-methyl-3,3-diphenylurea (akardite II). The presence of the first two molecules in GSRs was already reported before [10, 19-21], and they were detected in all the analysed residues even if they were not detected in the respective smokeless powders. In addition, akardite II (which was detected in gunshot exhausts for the first time in this work) was observed in four out of nine residues, but only in two smokeless powders. These observations are consistent with the nature of smokeless powder manufacturing. Indeed, it is not rare that manufacturers blend powder lots in order to achieve optimal ballistic performances [27]. Traces of minor compounds can thus be detected in GSRs, especially with a high-sensitive extraction technique such as HSSE. Some nitro-derivatives of diphenylamine (mainly, the isomers of the nitrodiphenylamine and the 2,4-dinitrodiphenylamine) were also identified in the GSRs of some cartridges. These 
are degradation products of smokeless powders, which are normally produced during cartridge ageing. However, previous researches reported that their formation could be significantly accelerated at high temperatures [28]. Thus, in-vial formation of these compounds during extraction at $80^{\circ} \mathrm{C}$ seems probable, considering that few of them were observed by extraction at $20^{\circ} \mathrm{C}$ of the same types of cartridges. Other identified aromatic nitro-compounds were nitrobenzene, nitrophenol and nitrotoluene. The last two molecules were already identified in the exhaust of military rifles [8] and detected in all the types of cartridges in our study. Considering their high thermolability, also these compounds were probably produced from the degradation of the different gunpowder additives rather than from explosion reactions. Dinitrotoluenes were never detected in GSRs (and neither in the smokeless powders), even after ion extraction.

Several substances containing hetero-atoms other than nitrogen were identified. Particularly, many compounds of sulphur (i.e. benzo[b]thiophene and dibenzothiophene) and oxygen (i.e. dibenzofuran) were observed in the residues of all the cartridges. Amongst these substances, only benzo[b]thiophene was previously reported in the literature [20]. Benzothiazole, an aromatic molecule containing both nitrogen and sulphur, was previously detected only in military rifle exhausts [8]. Sulphur probably originates from primer mixtures rather than smokeless powders. In fact, most producers currently use antimony sulphide to produce priming mixtures [29]. In addition, some aromatic aldehydes and alcohols, such as benzaldehyde, benzophenone and acetophenone, were also detected. Methylphenol was identified for the first time in this study. 4-Phenylazophenol, a yellow dye (Solvent Yellow 7), was found in the residue of two cartridges. As it is generally used as a celluloid colourant and lacquer component, it may be employed as an additive in smokeless powders [30]. Chlorinated aromatics (i.e. isomers of dichlorobenzene, dichlorophenol, chlorobenzaldehyde, dichlorobenzaldehyde and dichlorobenzamide) were found in the residues of all cartridges but remain unknown in the literature. Sources of chlorine in GSRs are difficult to track down. Modern primers are normally free of chlorates because of their corrosive properties [29]. It is supposed that chlorine originates from the degradation of plastic materials based on poly(vinyl chloride) [31]. Presence of the aforementioned compounds could thus be ascribable to a contamination due to the production and packing of the cartridges and/or specimen handling.

Phthalates are the esters of benzene-1,2-dicarboxylic acid. These compounds are commonly employed in the production of smokeless powders as plasticizers. Dibutyl phthalate is the most widely used and was already found in residues $[19,20]$. On the contrary, dimethyl, diethyl and dioctyl phthalates were previously identified only in smokeless powder formulations $[29,32]$. Particularly, dioctyl phthalate (also known as bis(2ethylhexyl) phthalate) is a very common phthalate-based plasticizer, produced from the reaction with 2-ethyl-1hexanol, which was also detected in the analysed GSRs. Salicylates (i.e. the esters of 2-hydroxybenzoic acid) and benzoates (i.e. esters of benzoic acid) share structural similarity with phthalates and were identified in residues. Salicylates are normally used as fragrances, while benzoates as carriers. Thus, they might be contaminations adsorbed on the cartridge surface.

Even though few aliphatic substances were previously identified in GSRs, several were observed in the analysed cartridges during this research. A large fraction was composed of linear alkanes and alkenes. In fact, linear alkanes from C11 to $\mathrm{C} 24$ and linear mono-alkenes from $\mathrm{C} 10$ to $\mathrm{C} 17$ were present in the exhausts of all the cartridges. Branched alkanes such as pristane and phytane were also detected. Even if these compounds were not found in the smokeless powders, it is very unlikely that they were produced during the explosion. In this regard, the couples heptadecane/pristane and octadecane/ phytane may indicate the presence of heavy petroleum distillates, such as mineral oils [33]. Thus, these groups of compounds might be ascribable to a contamination of spent cartridges by lubricants during the production process or cleaning of the weapon [34]. A similar mechanism could also explain the presence of methyl dehydroabietate (a marker of wood tar, generally used for waterproofing $[35,36])$ in the residues. Saturated fatty acids and related esters were another important class of aliphatic molecules found in GSRs. Lauric (C12:0), mystic (C14:0), palmitic (C16:0) and stearic acid (C18:0) were detected, along with some of their isopropyl and butyl ester derivatives. Given the fact that they were not found in the blanks, their presence might be the result of a contamination of the cartridge surface or vials by fingerprint residues [37, 38].

Amongst the other aliphatics, 2(5H)-furanone was already identified in the literature as an important pyrolytic byproduct of smokeless powder $[17,18]$ and was observed in all residues. Butyldihydro-2(3H)-furanone was firstly reported in this work and found to be very common amongst cartridges. Similarly, 1,4:3,6-dianhydro- $\alpha$-D-glucopyranose was previously identified as a main pyrolitic byproduct of cellulose [39]. Considering that the main explosive in smokeless powders is nitrocellulose, this could explain its presence in seven out of nine residues.

\section{Characteristics of GSRs from the different types of ammunition}

While an extraction temperature of $20^{\circ} \mathrm{C}$ proved to be useful to identify some of the most volatile compounds, $80^{\circ} \mathrm{C}$ generally allowed reaching higher recoveries. Consequently, only data acquired at this condition were considered hereafter.

Figure 2 shows the percentages of each class of compounds on the total sum of peak areas in TICs. As can be seen from the 


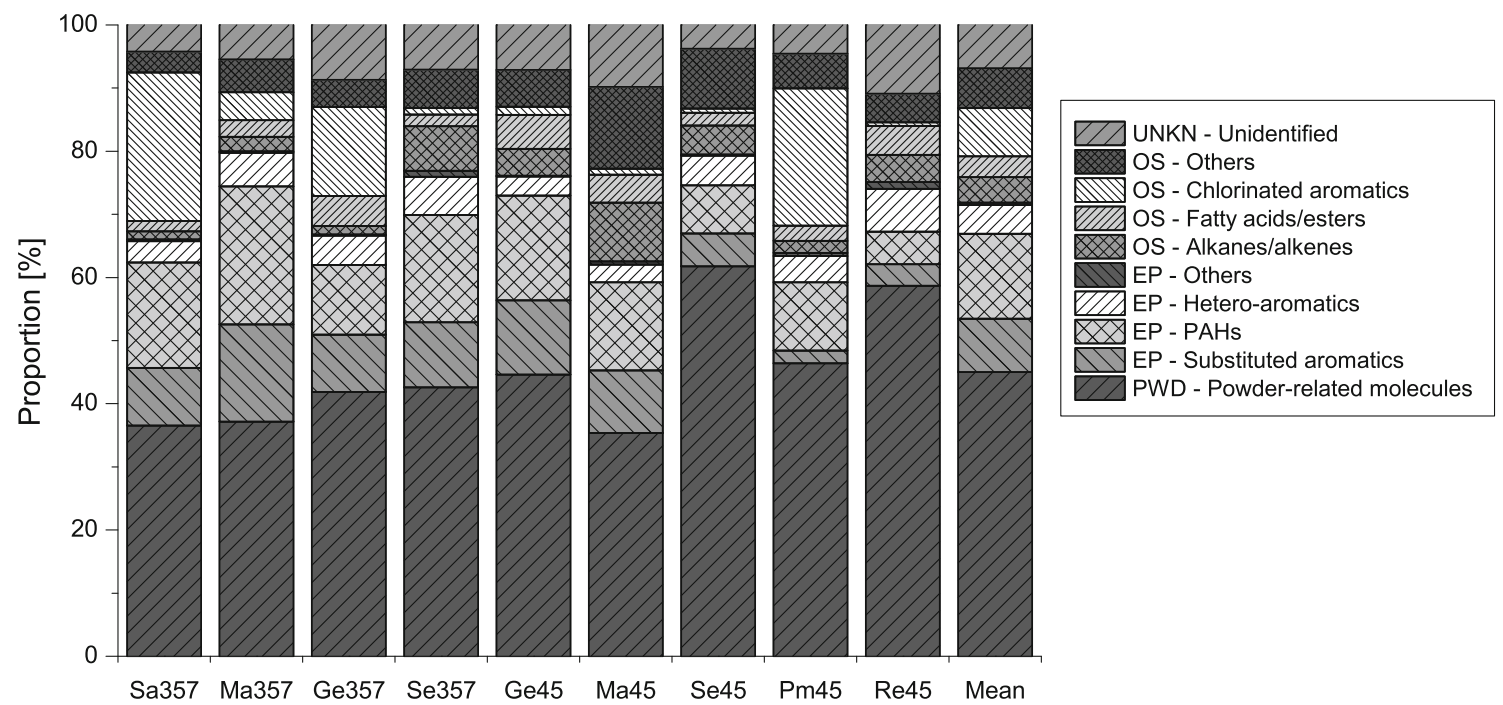

Fig. 2 Proportions in TICs of the different compound classes amongst all the analysed GSRs (after extraction at $80{ }^{\circ} \mathrm{C}$ ). $P W D$ smokeless powder additives, $E P$ explosion products, $O S$ other sources $U N K N$ unidentified compounds. Classes coincide with those reported in Table S2 in the ESM

figure, molecules coming from smokeless powder were always the dominant class, with proportions ranging from 36.6 to $61.8 \%$ (average, $45.0 \%$ ). This suggests that a significant amount of smokeless powder compounds were adsorbed on the inner cartridge walls and/or did not undergo combustion during explosion. Concerning the explosion products, branched/substituted aromatics and PAHs were normally the second most abundant classes in GSRs. Proportions for branched/substituted aromatics went from 5.2 to $15.4 \%$ (average, $8.5 \%)$. Internal composition of this class was strongly variable from one cartridge to another, but nitrile- and alkylsubstituted benzene derivatives always constituted the major sub-classes. PAHs proportion ranged from 5.2 to $17.0 \%$ (average, $13.4 \%$ ). Except for one type of ammunition (Pm45), PAHs mainly consists of two-ring compounds and the proportions for heavier PAHs decreased as a function of the number of rings. Prevalence of small aromatics is consistent with the discharge process. Indeed, the bullet departure is normally very rapid, and conditions promoting the addition of radicals onto smaller molecules are probably not held for a sufficient time to produce heavier molecules. However, it should also be noted that sampling was done through headspace extraction, which is less sensitive towards heavy molecules with low volatility. The other classes of explosion products were generally below $10 \%$. Particularly, the proportions of heteroaromatics were comprised between 2.8 and $6.8 \%$ (average, $4.5 \%$ ). This shows that, although hetero-atoms are partly involved in the process of pyrosynthesis of byproducts, their inclusion in molecular rings was very limited. The only exception was Re45, where the proportion of hetero-aromatics was slightly larger than that of the other explosion products. Proportions of alkanes/alkenes and fatty acids/esters ranged from 1.3 to $9.3 \%$ (average, $4.1 \%$ ) and from 1.6 to $5.4 \%$ (average, $3.3 \%$ ), respectively. Therefore, these compounds
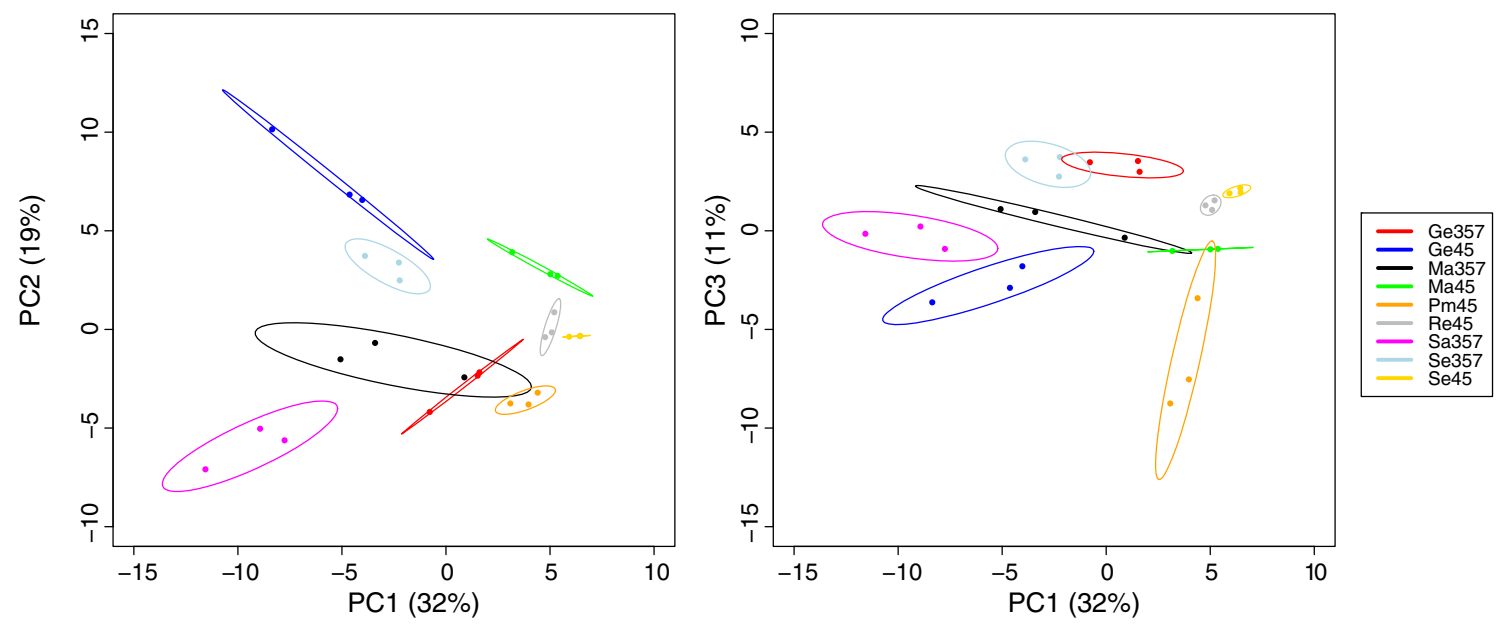

Fig. 3 Plot of the first three principal components (PC) after principal components analysis (PCA) of GSR data (extracted at $\left.80{ }^{\circ} \mathrm{C}\right)$. Only data concerning identified explosion products and smokeless powder additives were analysed. Explained variance of each PC is reported in brackets 

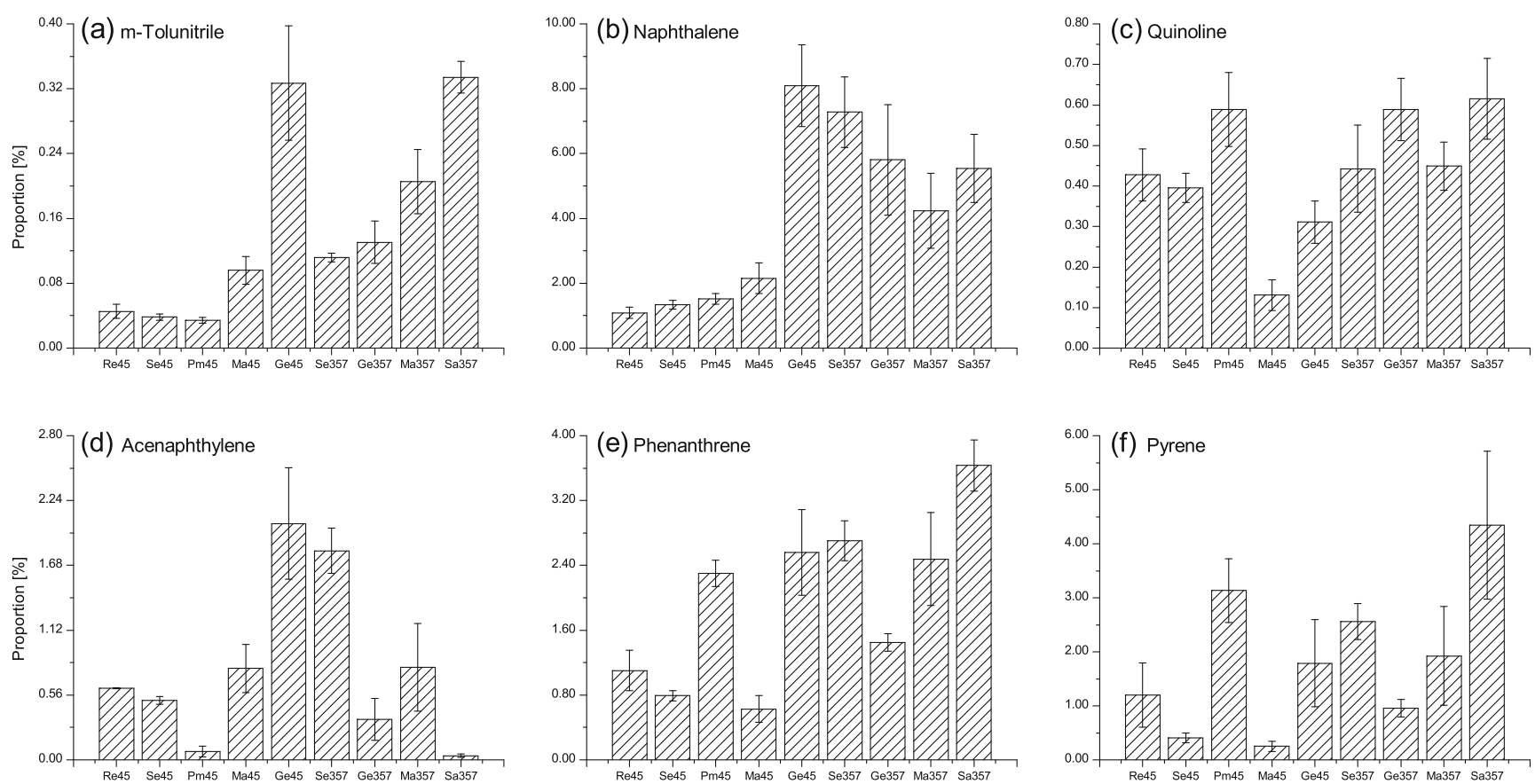

Fig. 4 Proportions for some selected compounds amongst cartridges

were not very abundant in the GSR profiles. On the contrary, the proportion of chlorinated aromatics ranged from 0.7 to $23.5 \%$ (average, $7.6 \%$ ) and consequently represented a significant percentage of the chromatograms of some cartridges (i.e. Sa357, Ge357 and Pm45).

Focusing only on smokeless powder additives and explosion products, results showed that the sum of their peak areas was dependent on the type of ammunition. This means that different sources also yielded different amounts of GSR by the employed method (ESM Fig. S1). However, no significant correlation between the signals and the initial quantity of smokeless powder in the cartridge was observed. In fact, many cartridges with very different initial quantities of powder gave similar peak area sums. For instance, $\mathrm{Pm} 45$ (5.1 gr of smokeless powder) showed comparable signals as Sa357 (17.2 gr). On the other hand, cartridges filled with similar powder weights could release different amounts of GSR. This is, for example, the case of Re45 (4.8 gr), which gave significantly lower signals compared to

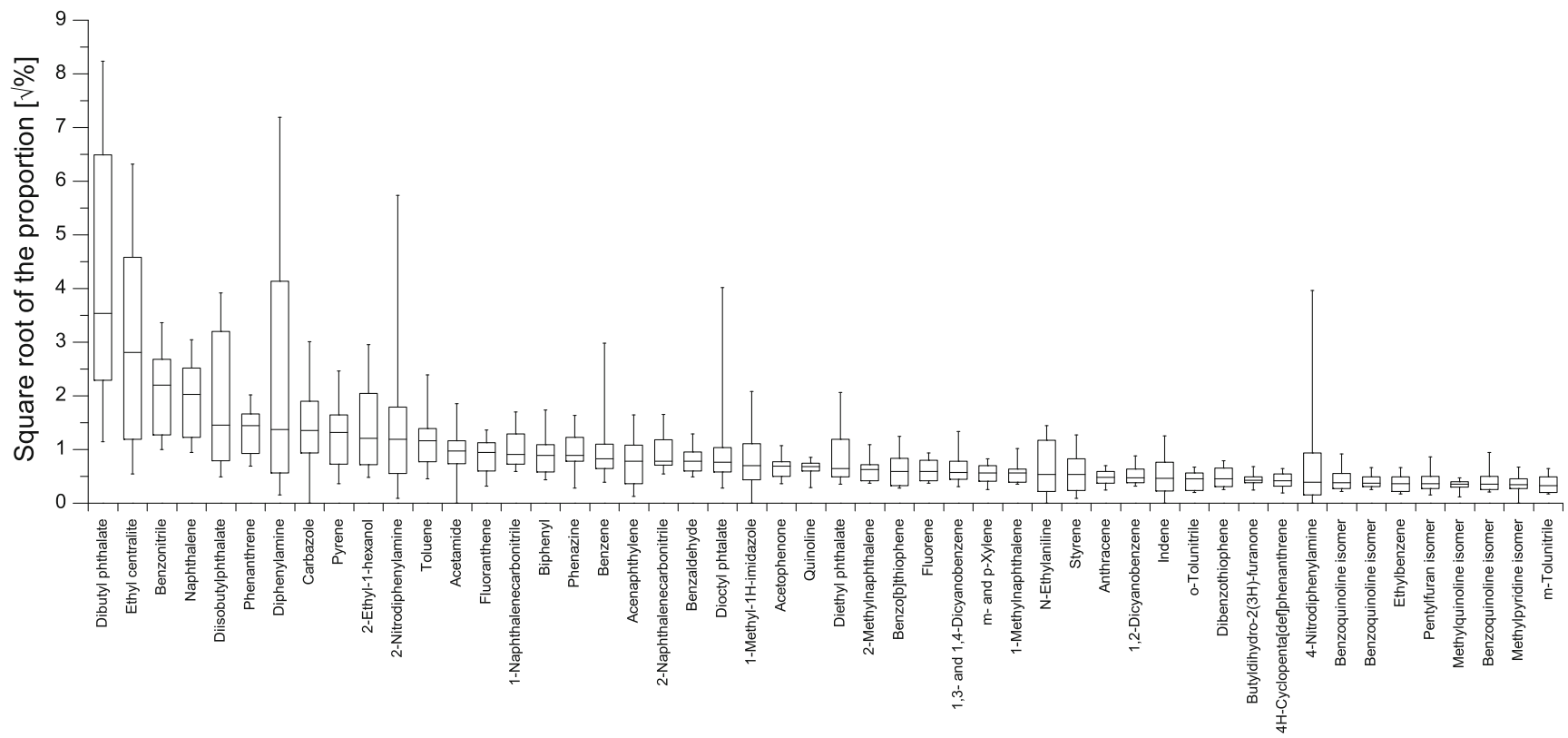

Fig. 5 Distribution amongst GSRs of the 50 most abundant explosion products and gunpowder additives (after extraction at $80{ }^{\circ} \mathrm{C}$ ). To improve graph readability, unit of $y$ axis is given as the square root of the proportion of the total sum of peak areas 
Se45 (5.0 gr). The diversity of smokeless powder ballistic properties (mainly, powder vivacity) is likely to be the cause of these observations. In fact, some powders undergo a more or less exhaustive explosion reaction than others and, thus, release different amounts of HSSE-detectable compounds.

Of the 166 identified compounds, 141 were found to be present in the GSRs of every cartridge, making their qualitative compositions very similar. Nonetheless, proportions between compounds were significantly different. These can be easily visualized using principal component analysis (PCA). Figure 3 shows the plot of the first three principal components after applying PCA solely on explosion products and gunpowder additives. GSRs belonging to different sources could be fairly discriminated, even if some of them shared quite similar compositions (i.e. Re45 and Se45). In order to better appreciate these differences, proportions for some selected compounds were plotted in Fig. 4.

Correlations between compounds were calculated, and it was found that molecules presenting similar structures were also strongly correlated. This was, for example, the case of phenanthrene and pyrene $(r=0.92)$, benzaldehyde and benzonitrile ( $r=$ $0.95)$, benzaldehyde and biphenyl $(r=0.94)$, m-tolunitrile and 1naphthalenecarbonitrile $(r=0.97)$ as well as naphthalene and 2methylnaphthalene $(r=0.80)$. This result is consistent with their formation process, which involves the sequential addition of radicals in order to form larger and larger molecules. Consequently, even if different proportions of the various explosion products could be released between different cartridge types, those sharing similar structures are more prone to be generated at the same time and to be correlated within the same ammunition. Moreover, the compounds in the previous couples also shared similar chemical properties (i.e. boiling point, vapour pressure and polarity), which makes their extraction behaviours very similar and contribute to the high observed correlations.

Smokeless powder formulation certainly affects postdischarge GSR composition. However, it is also true that cartridges using very similar powder formulations (i.e. Se45 and Se357, as well as Ma357 and Sa357) showed differentiable GSRs. In the same manner, the similitude between the residues released by Re 45 and Se 45 was very interesting because their pre-discharge smokeless powder formulations were found to be significantly different (Table 1). It can thus be deduced that other factors (e.g. pressure and temperature conditions during the discharge) may play an important role and therefore influence the composition of the GSRs. This was also supported by the fact that no significant correlation between the composition of the smokeless powders and the respective GSRs were observed (i.e. there was no evidence that a powder containing specific additives preferentially generated given compounds). Instead, it was already proved that parameters such as burning conditions during the combustion of organic matter are particularly relevant in controlling the pyrosynthesis of new species $[40,41]$.

\section{Identification of potential target compounds for time since discharge estimation}

Target analytes for dating purposes should fulfil the following criteria:

(1) always be released during the discharge (i.e. they should be present in the GSRs released by every type of cartridge)

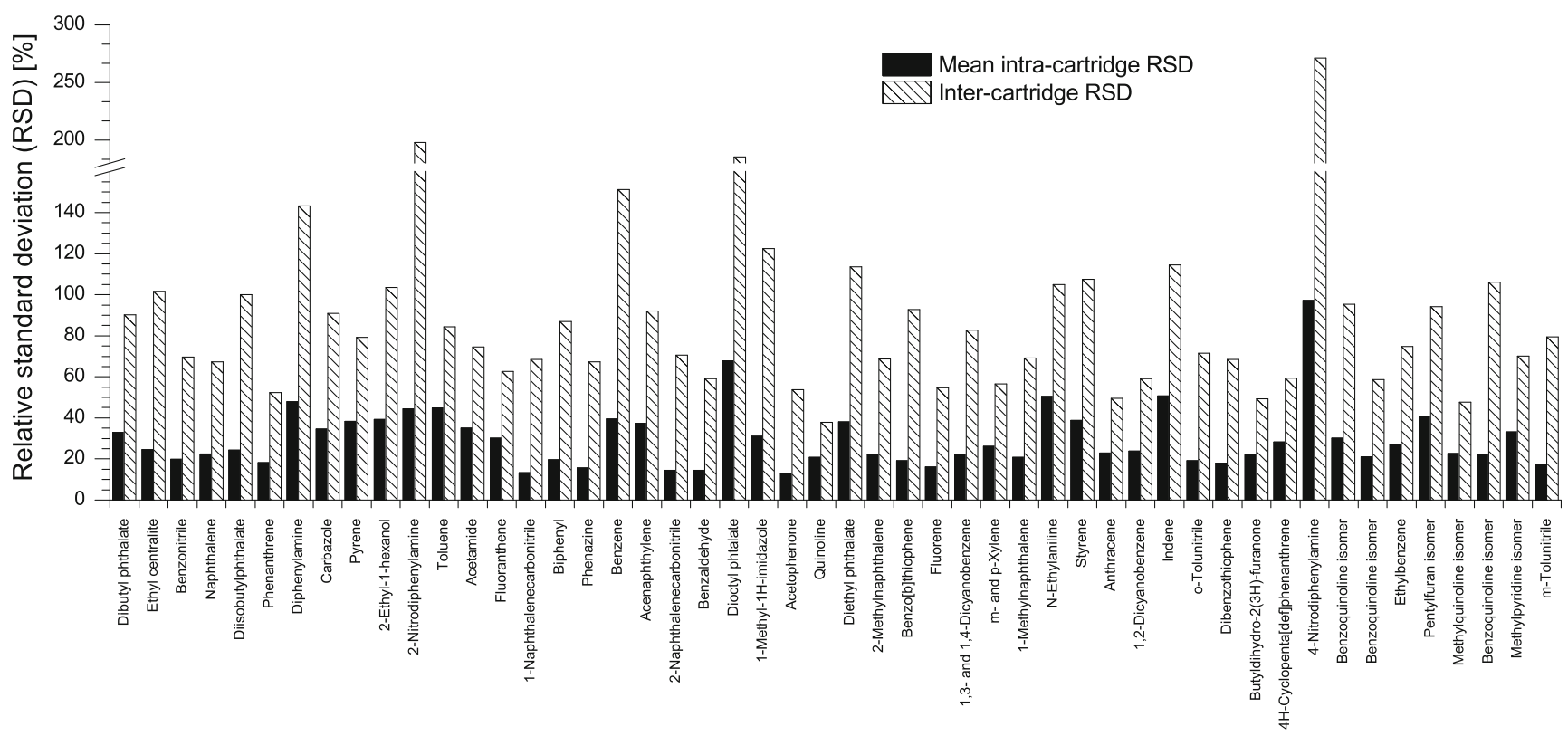

Fig. 6 Comparison of mean intra-cartridge RSDs and inter-cartridge RSDs amongst the different cartridges for the proportions of the 50 most abundant explosion products and gunpowder additives identified in GSRs (after extraction at $80{ }^{\circ} \mathrm{C}$ ) 
(2) ideally be present in high amounts

(3) their signals should show low intra-variability between the discharge of the same cartridge and firearm set

(4) their signals should show low inter-variability between different cartridge/firearm sets

(5) have a significant evolution during a relevant time range after discharge

These characteristics were investigated for each explosion product and smokeless powder additive previously identified in GSRs.

Firstly, variability of compounds at $t=0 \mathrm{~h}$ in all the analysed types of ammunition was studied. Amongst the identified explosion products and smokeless powder additives, only a few molecules were not observed in all the residues (ESM Table S2). These are mainly the heaviest PAHs (chrysene and benzo[a]pyrene), 1,4:3,6-dianhydro- $\alpha$-D-glucopyranose, toluene, phenyl thiocyanate, 1,2,3,4-tetrahydro-1,1,6trimenthylnaphthalene, isoquinoline, nitrotoluene, 2,4dinitrodiphenylamine isomers, 1-methyl-3,3-diphenylurea (akardite II) and dioctyl phthalate.

Figure 5 shows the distribution of the remaining compounds amongst the cartridges. It is noteworthy that smokeless powder additives generally composed a large fraction of the GSRs and were the most abundant substances detected in chromatograms (Fig. 5). This is especially true for dibutyl phthalate, ethylcentralite, diisobutylphthalate, diphenylamine, 2-ethyl-1-hexanol and 2-nitrodiphenylamine, which were, on average, the six most abundant smokeless powder additives detected in GSRs. Concerning explosion products, their proportions were usually smaller but still significant in many cases. In fact, benzonitrile (aromatic nitrile) and naphthalene (two-ring PAH) represented a relatively large fraction of each analysed GSR, similarly to phenanthrene (three-ring PAH), carbazole (three-ring hetero-PAH), pyrene (four-ring PAH), fluoranthene (four-ring PAH), biphenyl (two-ring PAH) and acenaphthylene (three-ring PAH), which were less abundant. Consequently, many aromatics with up to four rings could be quantitatively detected after the discharge of all the analysed types of ammunition.

Intra-variability was investigated (Fig. 6). It was found that the proportions of smokeless powder additives were slightly less reproducible within the different sources than those of explosion products. In fact, the mean intra-cartridge relative standard deviation (RSD) values for dibutyl phthalate, ethyl centralite and diphenylamine were of the order of 33, 25 and $48 \%$, while those of benzonitrile, naphthalene and phenanthrene were 20, 22 and $18 \%$, respectively. Globally, medians between mean intra-cartridge RSD values for compounds associated to smokeless powder and those associated to explosion products were 39 and $24 \%$, respectively.

Furthermore, the proportions of smokeless powder additives showed higher inter-variability than those of explosion products. In fact, the amount of smokeless powder additives in GSRs often ranged from trace to major-compound levels depending on the types of ammunition (Figs. 5 and 6). Intercartridge RSD values for dibutyl phthalate, ethyl centralite and diphenylamine were in the order of 90, 102 and $143 \%$, respectively. 2-Nitrodiphenylamine reached $198 \%$. For the sake of comparison, values for benzonitrile, naphthalene and phenanthrene were considerably lower: 70,67 and $52 \%$, respectively. Globally, medians between inter-cartridge RSD values obtained for the compounds associated to smokeless powder and those associated to explosion products were 121 and $75 \%$, respectively.

Ageing of compounds over time $(t>0 \mathrm{~h})$ was investigated for two specific types of ammunition, i.e. Ma45 and Ge45.

Table 2 List of compounds showing significant decrease after $24 \mathrm{~h}$ since discharge in at least one of the two tested types of ammunition (the "Ge45" and "Ma45" columns indicate for which cartridge the decrease was significant)

\begin{tabular}{|c|c|c|c|c|}
\hline Ref. & Compound & $t_{\mathrm{R}}$ & Ge45 & Ma45 \\
\hline 7 & Ethylbenzene & 5.655 & $\mathrm{x}$ & $\mathrm{x}$ \\
\hline 8 & m- and p-Xylene & 5.795 & & $\mathrm{x}$ \\
\hline 10 & Styrene & 6.160 & & $\mathrm{x}$ \\
\hline 9 & o-Xylene & 6.241 & $\mathrm{x}$ & $\mathrm{x}$ \\
\hline 28 & 1-Methyl-1H-imidazole & 7.106 & $\mathrm{x}$ & $\mathrm{x}$ \\
\hline 15 & Benzonitrile & 7.797 & $\mathrm{x}$ & $\mathrm{x}$ \\
\hline 31 & Indane & 8.673 & $\mathrm{x}$ & $\mathrm{x}$ \\
\hline 32 & Indene & 8.830 & & $\mathrm{x}$ \\
\hline 16 & o-Tolunitrile & 9.518 & $\mathrm{x}$ & $\mathrm{x}$ \\
\hline 17 & m-Tolunitrile & 9.661 & $\mathrm{x}$ & $\mathrm{x}$ \\
\hline 18 & p-Tolunitrile & 9.933 & $\mathrm{x}$ & $\mathrm{x}$ \\
\hline 20 & Benzyl nitrile & 10.611 & $\mathrm{x}$ & $\mathrm{x}$ \\
\hline 33 & Methylindene isomer & 10.955 & & $\mathrm{x}$ \\
\hline 34 & Azulene & 10.990 & & $\mathrm{x}$ \\
\hline 35 & Naphthalene & 11.579 & $\mathrm{x}$ & $\mathrm{x}$ \\
\hline 64 & Benzo $[\mathrm{b}]$ thiophene & 11.754 & $\mathrm{x}$ & $\mathrm{x}$ \\
\hline 22 & Ethenylbenzonitrile isomer & 11.885 & & $\mathrm{x}$ \\
\hline 3 & 1,4:3,6-Dianhydro- $\alpha$-D-glucopyranose & 12.064 & & $\mathrm{x}$ \\
\hline 23 & Ethenylbenzonitrile isomer & 12.212 & & $\mathrm{x}$ \\
\hline 68 & Indole & 13.943 & & $\mathrm{x}$ \\
\hline 36 & 2-Methylnaphthalene & 13.983 & $\mathrm{x}$ & $\mathrm{x}$ \\
\hline 37 & 1-Methylnaphthalene & 14.367 & $\mathrm{x}$ & $\mathrm{x}$ \\
\hline 39 & Biphenyl & 15.908 & $\mathrm{x}$ & $\mathrm{x}$ \\
\hline 40 & 2-Ethylnaphthalene & 16.241 & $\mathrm{x}$ & \\
\hline 42 & Ethenylnaphthalene isomer & 16.651 & & $\mathrm{x}$ \\
\hline 45 & Ethenylnaphthalene isomer & 17.045 & & $\mathrm{x}$ \\
\hline 46 & Diphenylmethane & 17.139 & $\mathrm{x}$ & $\mathrm{x}$ \\
\hline 48 & Acenaphthylene & 17.515 & & $\mathrm{x}$ \\
\hline 49 & Biphenylene & 17.677 & & $\mathrm{x}$ \\
\hline
\end{tabular}

Ref. refers to the corresponding reference number for the compound in Table $\mathrm{S} 2$ in the ESM 
Table 2 reports the list of compounds for which ageing was proved significant in at least one of the two tested cartridges. Excluding 1,4:3,6-dianhydro- $\alpha$-D-glucopyranose (which was not observed in all the residues), 27 compounds other than naphthalene were found to significantly decrease over the considered time. Amongst them, no other compound associated to smokeless powders was observed. Consequently, although smokeless powder additives were amongst the most abundant compounds detected in GSRs, they are poorly suitable as target compounds for dating purposes considering their large intraand inter-variability, as well as the absence of significant ageing in the first $24 \mathrm{~h}$ after the discharge. On the contrary, many explosion products containing up to three aromatic rings showed a significant decrease after $24 \mathrm{~h}$. Substituted benzenes (e.g. xylenes, benzonitrile, tolunitriles) were particularly represented. This is surely due to their low boiling points that render them very volatile. Additionally, naphthalene, methylnaphthalenes, biphenyl, diphenylmethane, biphenylene and acenaphthylene also showed considerable decrease. This does not apply to heavier PAHs such as phenanthrene and pyrene, at least during the considered time interval.

\section{Conclusions}

Headspace sorptive extraction (HSSE) followed by GC/MS analysis was employed to study the characteristics of volatile organic gunshot residues (GSRs) extracted from nine different types of ammunition.

One hundred sixty six compounds were identified. It was observed that a significant proportion of the total ion chromatograms was always dominated by smokeless powder additives which do not undergo explosion process during discharge. These were mainly amine-based and/or urea-based stabilizers such as diphenylamine and ethyl centralite, as well as their degradation products. Pyrolitic byproducts coming from the different explosion pathways were the most variegated group regarding the number of different species identified. Most of them were polycyclic aromatic hydrocarbons (PAHs) containing two and three rings (such as naphthalene, fluorene and acenaphthene) and alkyl-substituted benzenes. PAHs with up to five rings (i.e. chrysene) were nevertheless detected in the residues of some cartridges. Several molecules presenting hetero-atoms in their structures were also observed. These were mostly nitrogen-containing hetero-PAHs (e.g. quinoline and benzoquinoline) and aromatic nitriles (e.g. benzonitrile and naphthalenecarbonitrile). Compounds of sulphur and oxygen were also identified, but they were less common. Of the 166 identified compounds, 141 were found to be present in the GSRs of every cartridge, making the respective qualitative compositions very similar. Despite that, it was observed that the final quantitative compositional characteristics of each residue (i.e. proportions between the compounds) strongly depend on its source and could thus be very variable amongst different types of cartridges. Behaviour of the single compounds was studied more in-depth in order to identify adequate target analytes for dating purposes. Smokeless powder additives were found to be unsuitable because their relative quantities were less reproducible between and within sources and also because they did not show any significant decrease during the first $24 \mathrm{~h}$ after the discharge. On the other hand, many substituted aromatics and PAHs showed acceptable reproducibility and ageing behaviours. Besides naphthalene, 27 compounds proved to be interesting analytes for forensic dating purposes.

This is the first time HSSE was used for characterizing volatile organic compounds found in cartridges after their discharge and also that GSRs from so many sources were compared in the same study. The improved extraction sensitivity of HSSE in comparison to SPME allowed new compounds to be identified and, thus, to gain a better understanding of the composition, reproducibility and variability of the GSR volatile fraction. Many new dating-interesting compounds were found. This could be particularly useful for the development of novel approaches to estimate the time since discharge of spent handgun cartridges based on multiple analytes. Future works will need to focus on further optimization of the analytical procedure and the development of robust multivariate regression models.

Acknowledgments This work was kindly supported by the Swiss National Foundation (grant no. PP00P1_150742). The authors would like to thank Dr. Manuel Garcia Gongora, Thibault Genessay, Sarah Hochholdinger and Sonja Bitzer from the Institut de Police Scientifique (Lausanne, Switzerland) for their precious advice and for proofreading early drafts of this paper.

\section{References}

1. Chang KH, Jayaprakash PT, Yew CH, Abdullah AFL (2013) Gunshot residue analysis and its evidential values: a review. Aust J Forensic Sci 45(1):3-23

2. Meng H-H, Caddy B (1997) Gunshot residue analysis - a review. J Forensic Sci 42(4):553-570

3. Dalby O, Butler D, Birkett JW (2010) Analysis of gunshot residue and associated materials - a review. J Forensic Sci 55(4):924-943

4. Mach MH, Pallos A, Jones PF (1978) Feasibility of gunshot residue detection via its organic constituents, part I: analysis of smokeless powders by combined gas chromatography-chemical ionization mass spectrometry. J Forensic Sci 23(3):433-455

5. Mach MH, Pallos A, Jones PF (1978) Feasibility of gunshot residue detection via its organic constituents, part II: a gas chromatographymass spectrometry method. J Forensic Sci 23(3):446-455

6. Basu S (1982) Formation of gunshot residues. J Forensic Sci 27(1): 72-91

7. Wolten GM, Nesbitt RS (1980) On the mechanism of gunshot residue particle formation. J Forensic Sci 25(3):533-545

8. Ase P, Eisenberg W, Gordon S, Taylor K, Snelson A (1985) Propellant combustion product analyses on an M16 rifle and a 105mm caliber gun. J Environ Sci Health 20(3):337-368 
9. Moxnes JF, Jensen TL, Smestad E, Unneberg E, Dullum O (2013) Lead free ammunition without toxic propellant gases. Propellants, Explos, Pyrotech 38:255-260

10. Andrasko J, Norberg T, Stahling S (1998) Time since discharge of shotguns. J Forensic Sci 43(5):1005-1015

11. Andrasko J, Stahling S (1999) Time since discharge of spent cartridges. J Forensic Sci 44(3):487-495

12. Andrasko J, Stahling S (2000) Time since discharge of rifles. J Forensic Sci 45(6):1250-1255

13. Andrasko J, Stahling S (2003) Time since discharge of pistols and revolvers. J Forensic Sci 48(2):307-311

14. Wallace JS (2008) Chemical analysis of firearms, ammunition, and gunshot residue. CRC Press, Boca Raton

15. Richter H, Howard JB (2000) Formation of polycyclic aromatic hydrocarbons and their growth to soot: a review of chemical reaction pathways. Prog Energy Combust Sci 26:565-608

16. Ravindra K, Sokhi R, Van Grieken R (2008) Atmospheric polycyclic aromatic hydrocarbons: source attribution, emission factors and regulation. Atmos Environ 42:2895-2921

17. Cropek DM, Kemme PA, Day JM, Cochran J (2002) Use of pyrolysis GC/MS for predicting emission byproducts from the incineration of double-base propellant. Environ Sci Technol 36:4346-4351

18. Persin B, Touron P, Mille F, Bernier G, Subercazes T (2007) Évaluation de la date d'un tir. Can Soc Forensic Sci J 40(2):65-85

19. Weyermann C, Belaud V, Riva F, Romolo FS (2009) Analysis of organic volatile residues in $9 \mathrm{~mm}$ spent cartridges. Forensic Sci Int 186:29-35

20. Gallidabino M, Romolo FS, Bylenga K, Weyermann C (2014) Development of a novel headspace sorptive extraction method to study the aging of volatile compounds in spent handgun cartridges. Anal Chem 86:4471-4478

21. Wilson JD, Tebow JD, Moline KW (2003) Time since discharge of shotgun shells. J Forensic Sci 48(6):1298-1301

22. Tienpont B, David F, Bicchi C, Sandra P (2000) High capacity headspace sorptive extraction. J Microcolumn Sep 12(11):577-584

23. Splivallo R, Bossi S, Maffei M, Bonfante P (2007) Discrimination of truffle fruiting body versus mycelial aromas by stir bar sorptive extraction. Phytochemistry 68:2584-2598

24. Demyttenaere JCR, Morina RM, Sandra P (2003) Monitoring and fast detection of mycotoxin-producing fungi based on headspace solid-phase microextraction and headspace sorptive extraction of the volatile metabolites. J Chromatogr A 985:127-135

25. Romolo FS (2004) Organic gunshot residue from lead-free ammunition. Ph.D. thesis, University of Lausanne

26. Miller JN, Miller JC (2005) Statistics and chemometrics for analytical chemistry, 5th edn. Pearson Education Limited, Harlow
27. MacCrehan WA, Bedner M (2006) Development of a smokeless powder reference material for propellant and explosives analysis. Forensic Sci Int 163:119-124

28. Bergens A, Danielsson R (1995) Decomposition of diphenylamine in nitrocellulose based propellants, part I: optimization of a numerical model to concentration-time data for diphenylamine and its primary degradation products determined by liquid chromatography with dual-amperometric detection. Talanta 42(2):171-183

29. Wallace JS (1990) Chemical aspects of firearms ammunition. AFTE J 22(4):364-389

30. Allen RLM (1971) Colour chemistry. Appleton, New York

31. Jirackova-Audoin L, Bellenger V, Verdu J (1984) Influence of thermal degradation on the photooxidation of PVC. Polym Photochem 5:283-293

32. Keto RO (1989) Comparison of smokeless powders by pyrolysis capillary gas chromatography and pattern recognition. J Forensic Sci 34(1):74-82

33. Stauffer E, Dolan JA, Newman R (2007) Fire debris analysis. Academic, London

34. Arfsten DP, Johnson EW, Thitoff AR, Jung AE, Still KR, Brinkley WW, Schaeffer DJ, Jederberg WW, Bobb AJ (2005) Acute and subacute dermal toxicity of Break-Free CLP: a weapons cleaning and maintenance compound. J Appl Toxicol 25:318-327

35. Font J, Salvadó N, Butí S, Enrich J (2007) Fourier transform infrared spectroscopy as a suitable technique in the study of the materials used in waterproofing of archaeological amphorae. Anal Chim Acta 598:119-127

36. Jerkovic I, Marijanovic Z, Gugic M, Roje M (2011) Chemical profile of the organic residue from ancient amphora found in the Adriatic Sea determined by direct GC and GC-MS analysis. Molecules 16:7936-7948

37. Girod A, Ramotowski R, Weyermann C (2012) Composition of fingermark residue: a qualitative and quantitative review. Forensic Sci Int 223:10-24

38. Girod A, Weyermann C (2014) Lipid composition of fingermark residue and donor classification using GC/MS. Forensic Sci Int 238:68-82

39. Aho A, Kumar N, Eränen K, Holmbom B, Hupa M, Salmi T, Murzin DY (2008) Pyrolysis of softwood carbohydrates in a fluidized bed reactor. Int J Mol Sci 9:1665-1675

40. Masclet PA, Bresson A, Mouvier G (1987) Polycyclic aromatic hydrocarbons emitted by power stations, and the influence of combustion conditions. Fuel 66:556-562

41. Mastral AM, Callén MS (2000) A review on polycyclic aromatic hydrocarbon (PAH) emissions from energy generation. Environ Sci Technol 34(15):3051-3057 